\title{
Leuchtender Tumor weist dem Skalpell den Weg
}

Für das langfristige Fehlschlagen vieler Krebsoperationen ist neben Fernmetastasen das disseminierte Tumorwachstum verantwortlich: So streuen z.B. mehr als $20 \%$ aller gastrointestinalen Tumoren in das Peritoneum. Könnte er diese kleinen disseminierten Läsionen besser identifizieren, wäre dem Operateur ein radikaleres Vorgehen möglich.

Die Markierung mit grünem fluoreszierendem Protein (GFP), das aus einer Tiefseequalle stammt, lässt selbst einzelne Zellen intensiv strahlen und macht sie dadurch sichtbar, aber dazu müssen diese Zellen das GFP-Gen enthalten. US-amerikanischen und japanischen Onkologen und Chirurgen ist es gelungen, dieses Gen in ein Adenovirus einzubauen, das nur in Gegenwart einer aktiven Telomerase, d.h. ausschließlich in malignen Zellen replikationsfähig ist. In zwei Mäusemodellen, einem mit einem intraperitoneal disseminierten menschlichen Kolonkarzinom und einem mit einem in die Pleura disseminierenden menschlichen Bronchialkarzinom, konnten sie zeigen, dass ausschließlich malignes Gewebe sich durch helle grüne Fluoreszenz auszeichnet. In dem Darmkrebsmodell war es außerdem problemlos möglich, mithilfe dieser Markierung sämtliche Tumorläsionen restlos zu resezieren (Abb. 2).
Die Entwicklung von Fluoreszenzbeleuchtungen, die am Patienten anwendbar sind, sollte die Übertragung dieser Methode in den OP ermöglichen.

Kishimoto $\mathrm{H}$ et al. In vivo internal tumor illumination by telomerase-dependent adenoviral GFP for precise surgical navigation. Proc Natl Acad Sci USA 2009;106:14514-7.
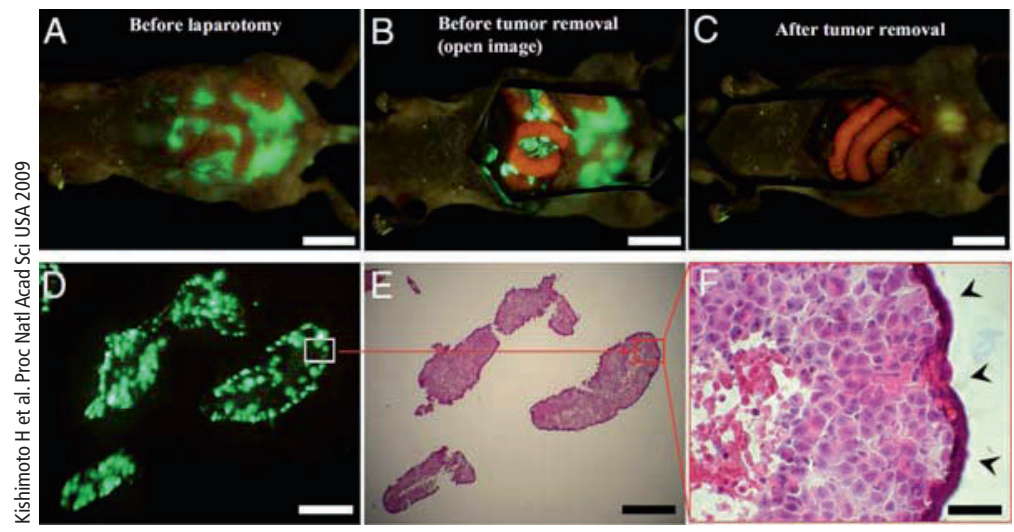

Abbildung 2. A. Maus, 15 Tage nach i.p. Injektion von menschlichen Kolonkarzinomzellen und fünf Tage nach Injektion des das GFP-Gen tragenden Adenovirus. B, C. Laparotomiebild vor und nach chirurgischer Entfernung aller leuchtenden Läsionen. D. Gefrierschnitt eines Resektats im Fluoreszenzlicht. Die Ausschnitte in E und F zeigen, dass es sich bei den leuchtenden Zellen um Tumorzellen handelt.

\section{Interferon und Antikörper steigern gegenseitig ihre Wirksamkeit}

Interferon $\alpha$ (IFN $\alpha$ ) wirkt direkt inhibitorisch auf eine Reihe von Tumoren und stimuliert auBerdem das angeborene ebenso wie das adaptive Immunsystem. Gelänge es, IFN $\alpha$ direkter an Tumorzellen heranzubringen, so überlegten USamerikanische Immunologen, könnte das die Antitumorwirkung potenzieren. Sie konstruierten daher Moleküle, in denen vier IFNa-Gruppen an den humanisierten Anti-CD20-Antikörper Veltuzumab gebunden sind (Abb. 3).

Diese als 20-2b bezeichneten Gebilde zeigten gegenüber CD20-positiven Zellen keine komplementabhängige, aber eine stärkere antikörperabhängige Zytotoxizität als Veltuzumab allein. In vitro konnten sie die Proliferation von Lymphomzellen hemmen und diese wirksamer aus menschlichem Blut entfernen als eine Kombination aus Veltuzumab und IFN $\alpha$, das an einen nicht gegen CD20 gerichteten Antikörper gebunden war. Obwohl die Immunzellen von Mäusen auf mensch- liches IFN $\alpha$ schlecht ansprechen, war 20-2b in drei Xenograftmodellen, in denen Mäusen menschliche Lymphome inokuliert werden, deutlich wirksamer als Veltuzumab allein. Offenbar lohnt es sich, IFN $\alpha$ gezielt an die Lymphomzellen heranzubringen; zumindest lassen diese Experimente die klinische Erprobung des Konstrukts sinnvoll erscheinen.

Rossi EA et al. CD20-targeted tetrameric interferon- $\alpha$, a novel and potent immunocytokine for the therapy of B-cell lymphomas. Blood 2009 [Epub ahead of print, DOI 10.1182/blood2009-06-228890].

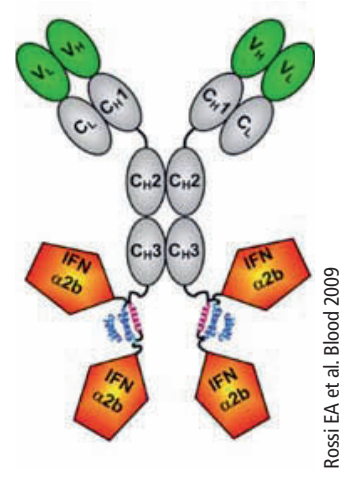

Abbildung 3. Das 20-2bKonstrukt aus dem Antikörper Veltuzumab und vier Interferonmolekülen. 